\title{
ON THE SYNTACTIC STATUS OF SMALL CLAUSE PARTICLES IN ENGLISH
}

\author{
Azusa YoKogoshi \\ Nagoya University
}

\begin{abstract}
This paper explores small clauses which contain particles such as as and for. It is well known that verbs like regard and take take particles in their small clauses. Until Middle English, it clearly functioned as preposition since only a DP appeared after as. Then it became to bear the properties of a functional element, i.e. $\operatorname{Pr}[$ edication]. This paper examines the property of small clause particle as and discusses what the categolrial status as has in present-day English. It will be shown that for in the take...for construction is not $\mathrm{Pr}$, but preposition.*
\end{abstract}

Keywords: small clause particle, Pr(edication), preposition, phase

\section{Introduction}

The main purpose of this paper is to examine the two types of constructions exemplified in the italicized parts of (1) and (2), respectively.

(1) a. They regard Mary as smart.

b. They regard him as a fool.

(2) a. They take Mary for a fool.

b. I took him for a doctor.

They consist of NP, as/for, and XP, which is regarded as constituting a small clause, with the NP and XP as its subject and predicate. In what follows, I will refer to as and for which occur in small clauses as

* This paper is an extended and revised version of the presentation I made at the workshop on Conference of the English Linguistic Society of Japan, held at Aoyama Gakuin University on November 15-17, 2002. I would like to express my gratitude to Masachiyo Amano and Tomoyuki Tanaka for invaluable comments and suggestions. My thanks also go to all of the members of Nagoya University for their helpful suggestions. I am also indebted to two anonymous $E L$ reviewers, whose comments and suggestions have led to substantial revisions. Needless to say, all remaining errors and inadequacies are my own. 
"small clause particles." As we will see shortly, the small clause particle as first appeared in Middle English with its prepositional properties, but it established its functional properties during the eighteenth century. Especially focusing on what properties as in present-day English has, this paper discusses the syntactic status of as and for in examples like (1) and (2), which I will henceforth call the regard...as construction and the take...for construction, respectively. Although the surface strings of these two constructions apparently look similar, it is argued that their small clause complements have different structures, on the basis of the distribution of pleonastic elements and the categories of the predicate phrases which may follow as and for.

This paper is conducted within the framework of the Minimalist Program advocated by Chomsky $(2000,2001)$, and the organization is as follows. Section 2 deals with the categorial change of the small clause particle as in the history of English. Section 3 introduces some differences between the regard...as and take...for constructions. Section 4 argues that for in the take...for construction is a preposition while as in the regard...as construction is a functional category $\operatorname{Pr}$ (edication) in the sense of Bowers (1993). Section 5 is a conclusion.

\section{As and the Categorial Change of Small Clauses in the History of English}

This section discusses the distribution of the small clause particle as in the history of English in order to clarify the categorial change of small clauses. According to Visser's (1963) observation, as did not appear in Old English small clauses. This fact would suggest that they involve no functional categories; in other words, they consist only of substantive categories.

In Middle English as began to appear within small clauses. However, it was not so productive until early Modern English. This fact would show that although as began to bear functional properties in Middle English, it had not established its functional status yet, so that its distribution was restricted in Middle and early Modern English. Tanaka (1998) examines the distribution of as in small clauses in the history of English. He examines the change of the categorial status of the elements following as, presenting the data below on the first occurrence of each category.

( 3 ) a. 1607 Shakes. Cor. V. vi 144 Let him be regarded As the 
most Noble Coarse, that euer Herald Did follow his Vrne

'Let him be regarded as the most noble corse that ever herald did follow to his urn'

b. 1706 Reflex. Upon Ridicule 39 They are regarded as inconversable, rough hewn, rude and phantasitical

(AP, VP)

'They are regarded as inconversable, rough hewn, rude and fantasitical'

( 4 ) a. 1387-8 T. Usk Test. Love ii. v. (Skeat) I. 63 Fairnesse of fieldes, ne of habitacions, ... maie not bee rekened as riches, ...

'Fairness of fields, none of habitations, ... but not be reckoned as riches, ...'

b. 1709 Hearne Collect. II. 294 Reasons..not reckon'd as sufficient for turning Mr. Littleton by his Degree (AP) 'Reasons..not reckoned as sufficient for turning $\mathrm{Mr}$. Littleton by his degree'

c. 1719 Waterland Vind. Christ's Div. 25 As if the Ray were not to be reckon'd to the Sun, as included in it

'As if the ray were not to be reckoned to the Sun, as included in it'

(Tanaka (1998: (35)-(36)))

Based on the above data, Tanaka argues as follows: in Middle and early Modern English, although as began to establish its functional status as a small clause particle, it still had prepositional properties since it could only take NP. Because of its prepositional properties, the distribution of as was restricted until early Modern English. During the eighteenth century AP and VP came to appear after as. By that time it lost its prepositional properties and was established as a functional category. If Tanaka's arguments are on the right track, it would follow that in present-day English as does not have prepositional properties, but it is indeed a functional category.

\section{The Nature of Predication in Small Clauses}

3.1. The Status of Postverbal NPs

Having suggested that as in present-day English is a functional category, let us examine the properties of the regard...as and take...for con- 
structions, beginning with the status of postverbal NPs. Many grammarians have analyzed the postverbal NPs in (1) and (2) as direct objects (cf. Quirk et al. (1985) among others). This analysis, however, is untenable. As Arimoto (1989) and Aarts (1992) observe, pleonastic elements like impersonal it and expletive there, which are semantically empty, can appear in the regard...as construction (but not in the take...for construction; see below).

( 5 ) a. I regarded there as being too many people present.

b. I regard there as being a lot of people. ${ }^{1}$

(Aarts $(1992: 112))$

(6) a. They regard it as impossible for him to win.

b. I regard it as obvious that he will win the game.

These examples clearly show that the NPs which follow regard cannot be analyzed as its direct objects, since pleonastic elements are not arguments and hence cannot occur in argument positions. Another reason comes from a consideration of the thematic structures of regard and take. The following examples indicate that the postverbal NPs in (1) and (2) have no thematic relationship with the matrix verbs.

( 7 ) a. \#They regard Mary.

b. \#They took Mary.

Rather, Mary is only associated with the small clause predicates, smart in (1a) and a fool in (1b), respectively. ${ }^{2}$ Furthermore, [NP as NP] strings can occur as constituents in positions other than the complement position of verbs. As shown by the examples in (8) and (9), the relevant strings can occur in the complement position of prepositions and the subject position, respectively.

( 8 ) a. I walked Safari with camels as pack animals.

b. He made a case for homosexuals as equals.

(9) Ian as chairman is not a good idea.

(Aarts (1992: 113))

${ }^{1}$ Some of my informants observe that the acceptability of this sentence is rather low.

${ }^{2}$ It should be noted that the NPs following regard are not always associated with the elements following them. Consider the examples below.

(i) a. I regarded her with honor.

b. I regard him highly.

In (i), it is clear that there is no subject-predicate relationship between the postverbal NPs and the elements following them. Therefore, these examples do not contain small clauses, so I will put them aside for the purposes of this paper. 
Therefore, it is plausible to conclude that the NPs which follow the matrix verbs in (1) and (2) are not direct objects, but subjects of their small clause complements.

\subsection{Differences between the Regard...as and Take...for Constructions}

It has often been pointed out in the literature that the small clause particles as and for exhibit syntactic behavior similar to prepositions which are homophonous with them. As illustrated in the following examples, preposition stranding is allowed in English, and small clause particles can also be stranded. ${ }^{3}$

(10) a. Who did you vote for?

b. Who did you talk to?

(11) a. Who do you take me for?

b. What do you regard him as?

Given this, it might be tempted to argue that as/for in the regard...as and take...for constructions are prepositions (see Arimoto (1989)). As we will see shortly, this is true of for in the take...for construction, but as in the regard...as construction is a functional category.

Some verbs optionally have small clause particles in their complements, as shown in (12).

(12) a. I consider her (as) the best friend.

b. I imagined her (as) a doctor.

However, verbs like regard and take obligatorily require small clause particles.

${ }^{3}$ It is well-known that in contrast to English, preposition stranding is impossible in French, Italian, and German.

(i) a. Who did you vote for? (English)

b. *Qui as-tu voté pour? (French)

c. *Chi hai votato per? (Italian)

d. *Wen stimmst du für? (German)

(Starke (1995: 243))

Small clause particles also show exactly the same pattern.

(ii) a. Who do you take me for?

What do you consider him as? (English)

b. *Qui me prends tu pour?

*Qu' est-ce que tu me considères comme? (French)

c. *Chi mi prendi per?

* Cosa mi consideri come? (Italian)

d. *Was hältst du mich für?

*Was betrachtest du mich als? (German)

(ibid.: 243) 
(13) a. I regard John *(as) my best friend.

b. They took John *(for) a fool.

c. They took John *(as) a fool.

(Rafel (2001: 493))

Pesetsky (1995) argues for selection of terminal elements that is referred to as "l-selection." $\mathrm{He}$ notes that "l-selection" involves arbitrary selection of lexical items, and features associated with this selection cannot be reduced to either s-selection or c-selection. ${ }^{4}$ Hence, it does not refer to syntactic categories, but makes reference to individual lexical items and specific features (e.g. [+/-finite]). Applying his analysis, I will assume that it is l-selection that is responsible for different selectional properties of verbs taking small clauses, including the facts that take selects small clauses with either as or for, regard selects small clauses with as, and consider/imagine select small clauses that optionally contain as.

Now let us consider the structures of the regard...as and take...for constructions. It might be argued that the two constructions have the same complement structure because of their surface similarity. Despite their similarity concerning postverbal NPs observed in the previous section, the following facts indicate that the small clauses in (1) and (2) have different structures. First evidence comes from a difference in the categories of elements following the small clause particles as and for. As illustrated in (14)-(16), NP, AP, and VP can follow as:

(14) a. They regard Mary as a fool. $\quad(=(1 \mathrm{~b}))$

b. I regarded him as a doctor.

(15) a. They regard Mary as smart. (=(1a))

b. I regarded him as foolish.

(16) a. They regard the book as given to Mary.

b. He regards his bag as stolen by that thief.

It is also possible for -ing forms to follow as. ${ }^{5}$

(17) a. They regard him as being a riot.

b. I regarded the bag as having been stolen by him.

On the other hand, while NP can follow for, AP and VP cannot, as

${ }^{4}$ Grimshaw (1991) argues that lexical entries of predicates contain information on c-selection which specifies the syntactic categories of their complements and s-selection which specifies the semantic types of their complements. Her claim is that there is no correspondence between c-selection and s-selection.

${ }^{5}$ I will return to the status of -ing forms in section 4.1.5. 
illustrated in (18)-(20). ${ }^{6}$

(18) a. They take Mary for a fool. $\quad(=(2 a))$

b. I take him for a genius.

(19) a. *They take Mary for smart.

b. *I take him for angry.

(20) a. *They took him for known to the police.

b. *His bag was taken for stolen by that thief.

Furthermore, -ing forms cannot follow for, either.

(21) a. *They take Mary for being a fool.

b. *I take there for being a lot of people.

As shown in (22), if take selects small clauses with as, AP, VP and -ing forms can follow as.

(22) a. They take Mary as smart.

b. They take me as known to the public.

c. They take him as being honest.

This difference between as and for would lead us to argue that as is a functional category that takes predicate phrases of any categories, while for is a substantive category as a preposition that takes only NP.

Second, the different distribution of pleonastic elements may also support the assumption that the regard...as and take...for constructions have different complement structures.

(23) a. I regarded there as being too many people present.

(Aarts (1992: 112))

b. I regard there as being a lot of people.

a. They regard it as pleasure to raise funds for an enterprise.

b. I regard it as foggy enough to cover our retreat.

(Postal (1974: 242))

(25) a. *I take there for being a lot of people.

b. *We take there for too many cars around the park.

(26) a. *I took it for fun to play the game.

b. *I take it for pleasure to pay the money.

As shown by these examples, expletive there and impersonal it can appear in the regard...as construction, but not in the take...for construc-

6 The only case in which other categories than NP can follow for is idiomatic expressions involving take...for granted, which I will put aside as exceptional.

(i) He takes it for granted that he is a popular man. 
tion. This would suggest that only the regard...as construction involves a functional category, because pleonastic elements like expletive there and impersonal it are generally taken to be inserted to satisfy the EPP feature of some functional category (Chomsky (2000, 2001)).

\section{The Structure of Small Clauses}

4.1. The Structure of the Regard...As Construction

Given the discussion in the previous section, the regard...as and take...for constructions are analyzed as having different structures. This section examines the internal structure of the regard...as construction, especially focusing on the syntactic status of the small clause particle as within the framework of the Minimalist Program. A number of researchers have analyzed the structure of small clauses involving as. Let us start by reviewing some of these analyses.

\subsubsection{PP Analysis}

First, let us consider the possibility that as is a preposition heading a small clause (see Arimoto (1989)). Since it is homophonous with the preposition as and can be stranded like prepositions (see (11b)), it might at first seem plausible that as in the regard...as construction is a preposition. However, in his comments on the regard...as construction, Starke (1995) notes that "P selects AP, an otherwise unattested fact" (see (15)). The PP analysis would have to allow for that sort of exceptional selection, which is obviously an undesirable move.

\subsubsection{CP Analysis}

A second possibility is to analyze as as a complementizer (see Hanston (1989) and Starke (1995)). One of the advantages of the CP analysis might come from the fact that the subordinate conjunction as can introduce a full sentence like the complementizer that, as shown in (27).

(27) I did as I was told.

(Rafel (2001: 477)) Under the $\mathrm{CP}$ analysis, the structure of the regard...as construction in (28) would be as in (29), where its subject moves from Spec-IP to Spec-CP.

(28) I regard them as being clowns.

(29) I regard [CP them ${ }_{i}$ [C as [IP $t_{i}$ [I [vp [v being [NP clowns]]]]]]] However, the CP analysis cannot account for the following passive 
sentences:

(30) a. They were regarded as being clowns.

b. The policy was regarded as having no effect.

(Aarts (1992: 115))

As Aarts (1992) and Rafel (2001) argue, in order to derive the passive sentence in (30a), for example, the subject would have to move from the embedded Spec-IP to the matrix Spec-IP, as represented in (31).

(31) $[\mathrm{e}]$ were regarded $[\mathrm{CP}[\mathrm{Spec}][\mathrm{C}$ as] [them being clowns]]

(ibid.: 115)

Since Spec-CP is not an argument position, this derivation involves improper movement, i.e. movement from an A-position to another Aposition via an A-bar position. This will pose a serious problem with the $\mathrm{CP}$ analysis.

One might claim that Spec-CP is no longer defined as an A-bar position within the framework of Chomsky $(2000,2001)$. In fact, the specifier position of $v \mathrm{P}$, which is assumed to be a phase, is treated as either an A- or A-bar position. It functions as an A position for the landing site of Object Shift and as an A-bar position for the intermediate landing site of $w h$-movement. So it might appear that the above argument based on Spec-CP as an A-bar position is not strong enough to reject the CP analysis.

In Chomsky (2000), the distinction between A- and A-bar positions depends on whether the relevant head has phi- or P(eripheral)-features, both of which are related to Agree. A-movement is implemented by Agree of phi-features, and A-bar-movement is implemented by Agree of P-features such as a $w h$-feature. Therefore, it is reasonable to assume that $\mathrm{C}$, a kind of force indicator, bears only $\mathrm{P}$-features, but not phifeatures. If so, in passive sentences like (30), the subject cannot move through Spec-CP, which in turn induces a violation of the Phase Impenetrability Condition (Chomsky $(2000,2001)$ ). This is because the subject in the embedded Spec-IP cannot be accessed from outside the embedded CP as a phase. Thus, the CP analysis should be rejected.

\subsubsection{IP Analysis}

Aarts (1992) regards as as an inflectional element and proposes the following structure of the small clause in (28), where its subject occupies Spec-IP.

(32) I regard [IP them [I as [VP [V being [NP clowns]]]]]

I will defer the examination of Aarts' analysis until section 4.1.5, where 
it is claimed that his analysis fails to explain some aspects of the regard...as construction, especially the distribution of expletive there.

\subsubsection{PrP Analysis}

This section introduces the PrP analysis of Bowers (1993). He argues that small clauses are PrPs headed by $\operatorname{Pr}($ edication), a functional category that is responsible for establishing a subject-predicate relationship. He further claims that as in the regard...as construction is a phonological realization of $\mathrm{Pr}$, and $\mathrm{Pr}$ is present even in small clauses where as does not appear. Under his analysis, the structure of the regard...as construction would be as in (33), where the subject of the small clause is base-generated in Spec-PrP.

(33) I regard [PrP Mary [ $\mathrm{Pr}$ as [AP [A smart]]]]

I will basically follow the PrP analysis of Bowers (1993), with some modifications discussed in the next section.

\subsubsection{Proposal}

Although Bowers (1993) assumes that the subject of small clauses is base-generated in Spec-PrP, there is good reason to assume that it is base-generated within the predicate phrase of small clauses. An argument for this assumption comes from the distribution of floating quantifiers.

(34) a. The cat considers the kids as all hopeless cases.

(Starke (1995: 242))

b. They regard the men as all foolish.

c. We regard the money as all stolen by the thief.

Sportiche (1988), among others, argues that a floating quantifier does not move rightward from the NP it is associated with, but when the NP moves from its base position, it leaves behind a floating quantifier there. If this is correct, it seems plausible that the subjects of the small clauses in (34) are base-generated in the specifier position of the predicate phrase and then move to Spec-PrP, as shown in (35).

(35) a. The cat considers $\left[\mathrm{PrP}_{\mathrm{r}}\right.$ the kids ${ }_{\mathrm{i}}\left[\mathrm{Pr}^{\prime}\right.$ as $\left[\mathrm{NP}\right.$ all $t_{\mathrm{i}}$ hopeless cases]]]

b. They regard [ $\mathrm{PrP}_{\mathrm{P}}$ the $\mathrm{men}_{\mathrm{i}}\left[\mathrm{Pr}_{\mathrm{r}^{\prime}}\right.$ as [AP all $\mathrm{t}_{\mathrm{i}}$ foolish]]]

c. We regard ${ }_{[\mathrm{Pr} P}$ the money ${ }_{\mathrm{i}}\left[\mathrm{Pr}^{\prime}\right.$ as $\left[\mathrm{vp}\right.$ all $\mathrm{t}_{\mathrm{i}}$ stolen by the thief]]]

It is generally assumed that the EPP requirement is present in small clauses. This is shown by the obligatory insertion of impersonal it in 
cases where small clauses do not have external arguments:

(36) a. We consider it impossible that he will win the game.

b. *We consider impossible that he will win the game.
a. They regard it as pleasure to raise funds for an enter- prise.
$(=(24 a))$
b. *They regard _ as pleasure to raise funds for an enter- prise.

Therefore, I will assume that in the regard...as construction it is also the EPP requirement of $\operatorname{Pr}$ that induces the movement of the small clause subject from its base position to Spec-PrP as represented in (35). There, it is assigned the value of accusative Case under agreement with the matrix $v$.

Now, consider the structure of the regard...as construction with an -ing form as the predicate phrase, in comparison with its structure in (35) with NP/AP/VP as the predicate phrase. Aarts (1992) argues that the regard...as construction has the same structure regardless of the kind of elements that follow as. The structure which he proposes for the sentences in (38) is presented in (39).

(38) a. They regard him as a fool.

b. They regard him as being a fool.

(39) They regard [IP him [I as [vp [v BE/being] [NP a fool]]]] $\mathrm{He}$ assumes that the category of -ing forms is a VP and as is an inflectional element. He also assumes that even when the predicate phrase of a small clause is not a VP, null $B E$ exists which indicates the subject-predicate relationship within the small clause. His analysis, however, is untenable when we consider the sentences in (40).

(40) a. I regard there as being a lot of people.

b. *I regard there as a lot of people.

These sentences show that the regard...as construction with expletive there becomes ungrammatical if there is no overt verb after as. Aarts cannot explain the contrast between $(40 \mathrm{a}, \mathrm{b})$ : under his IP analysis, there could be merged in Spec-IP regardless of the phonetic content of $\mathrm{V}$.

Importantly, what (40b) shows is that there cannot be merged in Spec-PrP to satisfy the EPP feature of $\operatorname{Pr}$ (which will be accounted for in the next section in terms of the hypothesis that $\operatorname{PrP}$ is a phase in the sense of Chomsky $(2000,2001))$. On the other hand, it would follow from the grammaticality of (40a) that there can be raised to Spec-PrP, assuming that -ing forms are TPs whose specifier there can be merged 
in. This will lead us to the following structure of (40a).

(41) I regard $\left[\mathrm{PrP}_{\mathrm{P}}\right.$ there ${ }_{\mathrm{i}}\left[\mathrm{Pr}^{\prime}\right.$ as $\left[\mathrm{TP} \mathrm{t}_{\mathrm{i}}[\mathrm{T}\right.$ being $[\mathrm{NP}$ a lot of people]]]]]

In (41), TP inside the small clause is headed by a defective $\mathrm{T}$ which is unable to determine Case/agreement. There is merged in Spec-TP and raised to Spec-PrP to satisfy the EPP feature of Pr. Then, the associate $\mathrm{NP}$ a lot of people is assigned the value of accusative Case under agreement with the matrix $v$.

This analysis can be extended to the contrast between $(42 a, b)$.

(42) a. I consider there likely to be a man in the room.

b. ${ }^{*}$ I consider there a man in the room. (Lasnik (1992: 384)) In (42a), there is merged in Spec-TP of the raising infinitive embedded under the small clause and raised to Spec-PrP to satisfy the EPP feature of Pr. On the other hand, the ungrammaticality of $(42 \mathrm{~b})$ indicates that there cannot appear in small clauses in the absence of TP whose specifier it can be merged in, which in turn implies that there cannot be merged in Spec-PrP. ${ }^{7}$

\subsection{6. $\operatorname{Pr} P$ as a Phase}

In the structures proposed in (35) and (41), substantive projections are selected by the functional category $\operatorname{Pr}$ (assuming that $\mathrm{T}$ is a substantive category; Chomsky (2001)). ${ }^{8}$ In the framework of Chomsky (2001), phases are defined as the configuration of the form F-XP, where the XP

7 On might wonder whether -ing forms inside small clauses are indeed TPs like infinitival clauses. Support for the TP status of -ing forms would come from the following pair of sentences:

(i) a. I regard him as obnoxious.

b. I regard him as being obnoxious.

There is no difference in meaning between the two sentences. It is important to note that (ib) does not denote action, unlike the following sentence involving being as a participle.

(ii) $\mathrm{He}$ is being obnoxious.

Therefore, being which follows as in the regard...as construction is not a participle, but a gerund. Since there have been a number of arguments presented in the literature that gerunds involve TP (Reuland (1983), Kayne (1984), and Arimoto (1991)), I will keep to the assumption that -ing forms inside small clauses are TPs whose specifier there can be merged in.

${ }^{8}$ Even under the DP hypothesis advocated by Abney (1987), it should be noted that nominal phrases following as are substantive projections NP without D, because they are predicative and $\mathrm{D}$ as a locus of referentiality only exists if the relevant nominal phrases are referential (Chomsky (2000)). 
is a substantive root projection and its category is determined by the functional category $\mathrm{F}$ that selects it. Therefore, it would be reasonable to assume that $\operatorname{PrP}$ is a phase like $v \mathrm{P}$ and $\mathrm{CP}$.

It will be important to note some differences between $\operatorname{PrP}$ and the other phases $v \mathrm{P}$ and $\mathrm{CP}$. As mentioned in section 4.1.2, the distinction between A- and A-bar positions depends on whether the relevant head has phi- or P-features in the framework of Chomsky (2000). Given this distinction, we can distinguish among PrP, $v \mathrm{P}$, and $\mathrm{CP}$ in terms of the features of their heads. $\mathrm{C}$ may have a P-feature as a force indicator, but cannot have phi-features. $\operatorname{Pr}$ may have both phi- and P-features, and this property allows $\operatorname{PrP}$ to behave like $v \mathrm{P}$. Therefore, the specifier positions of $v \mathrm{P}$ and $\mathrm{PrP}$ can function as A-bar positions for the intermediate landing site of $w h$-movement. However, $\operatorname{Pr}$ differs from $v$ in that $\operatorname{Pr}$ is not phi-complete and hence it does not determine Case/ agreement. Moreover, Pr obligatorily has the EPP feature unlike $v$.

As we saw in the previous section, expletive there cannot be merged in Spec-PrP (see (40) and (42)). This will follow from the assumption that PrP is a phase. According to Chomsky (2000), a phase head may be assigned an EPP feature when the phase has been completed, exhausting the lexical subarray from which it is derived. Given this, the EPP feature of a phase head must be satisfied by raising from within the phase. This is possible in (40a) and (42a), because TP is embedded under the small clause whose specifier there can be merged in. On the other hand, there cannot be merged in Spec-PrP in (40b) and (42b): it must be merged somewhere within PrP before the EPP feature is assigned to $\mathrm{Pr}$, but this is impossible simply because there are no functional categories other than $\mathrm{Pr}$ within the small clause which provides a specifier which there can be merged in.

\subsection{The Structure of the Take...For Construction}

As we saw in section 3, the small clause particle for in the take...for construction is analyzed as a preposition since it lacks functional properties in that it can only be followed by NP and the small clause does not allow pleonastic elements. Then, the structure of the take...for construction consists only of substantive projections, as shown in (43).

(43) They take [PP Mary [P for [NP a fool]]]

In this structure, the small clause subject is base-generated in Spec-PP; it is not raised there from the specifier position of the predicate phrase. An argument for this assumption comes from the following fact. 
(44) *They take the men for all fools.

Under the analysis of floating quantifiers proposed by Sportiche (1988), it follows from the ungrammaticality of (44) that the small clause subject does not originate inside the predicate phrase in the take...for construction, unlike the small clause subject in the regard...as construction (see (34)).

Thus, the take...for construction involves a small clause, namely a subject-predicate relationship, without $\operatorname{Pr}$ or any functional categories. In this respect, this construction may be exceptional, but the PP status of its small clause is supported by a number of empirical facts presented above. This poses a serious challenge for Svenonius' (1996) view that all instances of predication involve the functional category $\mathrm{Pr}^{9}$

\subsection{The Describe...As Construction}

Finally, this section discusses the describe...as construction as in (45).

(45) a. They describe Mary as smart.

b. They describe him as a fool.

At first glance, it might be expected that the describe...as construction shares the same type of small clause as the regard...as construction. This expectation might come from the fact that like the regard...as construction, small clauses which describe takes consist of NP, as, and XP, and the XP following as may be the categories of NP, AP, VP, and TP (-ing form). In fact, Quirk et al. (1985) do not distinguish between the regard...as and describe...as constructions. However, there are at least two arguments that these two constructions have quite different complement structures.

First, Aarts (1992) argues that describe assigns a $\theta$-role to the NP that follows it, on the basis of the following examples.

(46) a. They describe Mary as smart.

b. They describe him.

9 As we saw in (24), impersonal it may appear in the regard...as construction in the absence of -ing forms (=TP) following as. This will indicate that it is merged in the specifier of the predicate phrase and then raised to Spec-PrP to satisfy the EPP feature of Pr. The ungrammaticality of (26) would then show that it cannot remain within substantive projections, but must be raised to the functional domain for some reason(s) yet to be clarified. Also left open is the difference between it and there in the positions of first merger: the former is merged within substantive projections, while the latter is merged within functional projections, especially TP. 
(47) a. I described him as a fool.

b. I described him.

The grammaticality of the (b) sentences in (46) and (47) shows that the postverbal NP in the describe...as construction has a thematic relation with the verb as its direct object.

The second argument comes from the distribution of expletive there and impersonal $i t$.

(48) a. *I described there as being a fool.

b. *I described there as being a lot of people.

a. *I described it as raining all day.

(Aarts (1992: 117))

b. *They describe it as a honor to meet the president.

The ungrammaticality of these examples indicates that the postverbal NP in the describe...as construction is an argument of the verb and hence should not be treated as a small clause subject. Therefore, it follows from these arguments that the structure of the describe...as construction is different from that of the regard...as construction.

Here adopting Larson's (1988) VP-shell, I will propose the following structure for the describe... as construction.

(50) [vP They [v $e$ [vP Mary [v describe $\left[{ }_{\mathrm{PrP}}\right.$ PRO $\left[\mathrm{Pr}_{\mathrm{Pr}}\right.$ as $[\mathrm{AP}$ smart]]]]l]]

In (50), the postverbal NP Mary is base-generated in Spec-VP and describe moves from the lower $\mathrm{V}$ to the upper V. PRO, as, and smart form a small clause and PRO is controlled by Mary. ${ }^{10}$ Thus, the describe...as construction involves object control. ${ }^{11}$

10 Chomsky and Lasnik (1993) argue convincingly that PRO has Case. For detailed discussion, see Martin (2001).

11 Other verbs that behave like describe are understand, appoint, choose, elect, and so on.

(i) a. I didn't understand them as individuals.

b. He appointed me as his agent.

c. We choose this problem as easier.

d. He is elected as chairman.

Appoint and elect only allow NP to appear after as. This fact will be due to the property of these verbs that they denote an action which assigns some status to someone, where the status is typically expressed by NP. In such cases, as might be analyzed as a preposition, but not as a $\mathrm{Pr}$. 


\section{Conclusion}

In Middle English as first appeared in small clauses with prepositional properties. During the eighteenth century as lost them and established its functional status. Therefore, as in the regard...as construction is a functional category in present-day English.

This paper proposed that the regard...as and take...for constructions are analyzed as having different structures. The evidence for this proposal comes from the distribution of pleonastic elements and the categories of elements following as and for. In the structures proposed here, as in the regard...as construction is a functional category Pr, while for in the take...for construction is a preposition.

This paper also examined the possibility that small clauses are phases. Chomsky (2001) defines phases as configurations of the form F-XP, which led us to claim that $\operatorname{PrP}$ is also to be treated as a phase. The argument for this claim comes from the fact that expletive there cannot be merged in Spec-PrP. On the other hand, if small clauses have TP embedded under them, there can be merged in Spec-TP and then moves to Spec-PrP to satisfy the EPP feature of Pr.

\section{REFERENCES}

Aarts, Bas (1992) Small Clauses in English, Mouton de Gruyter, Berlin.

Abney, Steven Paul (1987) The English Noun Phrase in Its Sentential Aspect, Doctoral dissertation, MIT.

Arimoto, Masatake (1989) "The Distribution of Pleonastic Elements and Complement Structure of English," Studies in English Literature 66, 65-80.

Arimoto, Masatake (1991) "Hi-Taikaku-Koubun ni Okeru There Sounyuu to Shousetu no Kouzou (There-Insertion in the Unaccusative Verb Construction and the Structure of Small Clauses)," Eigo Seinen 136, 508-511, 569$571,637-640$.

Bowers, John (1993) "The Syntax of Predication," Linguistic Inquiry 24, 591656.

Chomsky, Noam (2000) "Minimalist Inquiries," Step by Step: Essays on Minimalist Syntax in Honor of Howard Lasnik, ed. by Roger Martin, David Michaels and Juan Uriagereka, 89-155, MIT Press, Cambridge, MA.

Chomsky, Noam (2001) "Derivation by Phase," Ken Hale: A Life in Language, ed. by Michael Kenstowicz, 1-52, MIT Press, Cambridge, MA.

Chomsky, Noam and Howard Lasnik (1993) "The Theory of Principles and Parameters," Syntax: An International Handbook of Contemporary Re- 
search, ed. by Joahim Jacobs, Armin von Stechow, Wolfgang Sternefeld and Theo Vennemann, 506-569, Walter de Gruyter, Berlin.

Grimshaw, Jane (1991) Extended Projection. ms., Brandeis University.

Hanston, Andre (1989) "The Complementizer 'As'," Sentential Complementation and the Lexicon, ed. by Danny Jaspers, Wim Klooster, Yvan Putseys and Pieter Seuren, 207-219, Foris, Dordrecht.

Kayne, Richard (1984) Connectedness and Binary Branching, Foris, Dordrecht.

Larson, Richard K. (1988) "On the Double Object Construction," Linguistic Inquiry 19, 335-391.

Lasnik, Haward (1992) "Case and Expletives: Notes toward a Parametric Account," Linguistic Inquiry 23, 381-405.

Martin, Roger (2001) "Null Case and the Distribution of PRO," Linguistic Inquiry 32, 141-166.

Pesetsky, David (1995) Zero Syntax: Experiencers and Cascades, MIT Press, Cambridge, MA.

Postal, Paul (1974) On Raising, MIT Press, Cambridge, MA.

Quirk, Randolph, Sidney Greenbaum, Geoffrey Leech and Jan Svartvik (1985) A Comprehensive Grammar of the English Language, Longman, London.

Rafel, Joan (2001) "As for As/For, They Are Semi-Lexical Heads," Semi-lexical Categories, ed. by Norbert Corver and Henk van Riemsdijk, 475-503, Mouton de Gruyter, Berlin.

Reuland, Eric J. (1983) "Governing -ing," Linguistic Inquiry 14, 101-136.

Sportiche, Dominique (1988) "A Theory of Floating Quantifiers and Its Corollaries for Constituent Structure," Linguistic Inquiry 19, 425-449.

Starke, Michal (1995) "On the Format for Small Clauses," Syntax and Semantics 28: Small Clauses, ed. by Anna Cardinaletti and Maria Teresa Guasti, 237-269, Academic Press, New York.

Svenonius, Peter (1996) "Predication and Functional Heads," WCCFL 14, 493507.

Tanaka, Tomoyuki (1998) "On the Rise of EPP Effects in Small Clauses," paper presented at the 16th Annual Meeting of the English Linguistic Society of Japan.

Visser, Frederik Theodoor (1963-1973) A Historical Syntax of the English Language, 4 vols., E. J. Brill, Leiden. (Vol. I, 1963: Vol. II, 1966; Vol. III, first half, 1969; Vol. III, second half, 1973)

3-4-16 Tokugawayama-cho

Chikusa-ku, Nagoya-shi

Aichi 464-0031

e-mail: a030137d@mbox.nagoya-u.ac.jp 